\title{
AINDA A EDUCAÇÃO POLITÉCNICA: O NOVO DECRETO DA EDUCAÇÃO PROFISSIONAL E A PERMANÊNCIA DA DUALIDADE ESTRUTURAL
}

\author{
STILL POLYTECHNIC EDUCATION:THE NEW DECREE ON PROFESSIONAL EDUCATION \\ AND THE PERMANENCE OF STRUCTURAL DUALISM
}

José Rodrigues 1

Resumo O ensaio analisa o recente decreto sobre educação profissional, $n^{\circ} 5.154 / 04$, considerando os limites estruturais impostos pelo modo de produção capitalista à educação, que se manifestam no fenômeno da dualidade estrutural escolar. A partir daí, retoma a concepção de educação politécnica, como um (ainda) novo horizonte de debate teórico, político e pedagógico para o campo da educação profissional.

Palavras-chave educação politécnica; reforma da educação profissional; legislação educacional brasileira; politecnia; educação tecnológica.
Abstract This article analyses the recently promulgated 5.154/04 decree on pro fessional education, taking into account the structural limitations imposed by capitalism on education, ma$\mathrm{n}$ i fested in the structural dualism of the school system. From there on, the article brings back the idea of polytechnic education as (still) a new perspective for the theoretical, political and pedagogical debate on professional education.

Key words polytechnic education; professional education reform; Brazilian legislation on education; polytechnic thinking; technological education. 


\section{Considerações preliminares}

Na década de 1980, o cenário educacional brasileiro foi palco de um forte debate, em cujo centro encontrava-se em disputa a reestruturação do sistema educacional brasileiro erigido durante o regimeautoritário, instaurado pelo golpe militar em 1964. Toda a cena política brasileira, inclusive o campo da saúde pública, passava por um processo catártico de repensar profundamente o seu passado recente e de instaurar, a partir daí, as novas bases para a aventura da reconstrução da cidadania usurpada e reprimida.

Nesse contexto histórico, precisamente em dezembro de 1987, durante o Seminário Choque Teórico, promovido pelo então Politécnico da Saúde Joaquim Venâncio (atual Escola Politécnica de Saúde Joaquim Venâncio), Derme val Saviani apresenta o texto intitulado Sobre a concepção de politecnia (Saviani, 1989). O trabalho de Saviani torna-se, sem dúvida, um marco no debate brasileiro da área trabalho e educação, em particular sobre as relações entre o ensino médio e o ensino técnico. A partir desse marco, muitos debates e dive rsas publicações são produzidos com o fito de buscar novos rumos para a educação brasileira, especialmente para a superação (ou, pelo menos, o enfrentamento) da dualidade estrutural que historicamente marca as concepções e práticas educativas no Brasil.

Embora nunca tenha se encerrado, o debate sobre a relação entre ensino médio e técnico — visto pela ótica da politecnia — ficou relativamente restrito a poucos interessados, mesmo após a promulgação do decreto $\mathrm{n}^{\circ}$ 2.208/97, que instituiu a chamada Reforma da Educação Profissional, ainda no primeiro governo Fernando Henrique Cardoso (1995-1998).

Finalmente, o debate sobre a concepção de politecnia parece reavivarse a partir do novíssimo decreto sobre a educação profissional $n^{0} 5.154 / 04$, promulgado no governo Lula em julho de 2004.

A partir daí, grosso modo, dois grupos se posicionam em torno da avaliação deste decreto. De um lado, aqueles que entendem ser o atual decreto o único caminho possível em direção ao enfrentamento da dualidade educação profissional versus ensino médio, enquanto outros percebem que o decreto, pretendendo ser 'realista', acaba por naturalizar a dualidade. $\mathrm{Cu}$ riosamente, ambos os grupos reivindicam-se partidários da concepção de educação politécnica e contrários à dualidade educacional, considerada milenar e fruto da luta de classes.

O que fazer diante de interesses antagônicos em luta ao longo da história? Se a dualidade é milenar, anterior ao modo de produção capitalista, se não é uma invenção autônoma da escola contemporânea, o que caberia fazer?

Pensamos que cabe uma análise radical da política educacional vigente e, simultaneamente, a retomada urgente do debate sobre a concepção de educação politécnica. 
Em síntese, este ensaio pretende levantar alguns questionamentos sobre o novo decreto sobre a educação profissional, propriamente dito, traçando algumas considerações acerca dos limites estruturais impostos pela sociedade capitalista à educação, além de retomar o debate teórico, político e pedagógico, da década de 1980, sobre a concepção de educação politécnica.

\section{Novo decreto, dualidade e flexibilidade 2}

Como já foi apontado, em 23 de julho de 2004, o presidente da República Luiz Inácio Lula da Silva cumpriu um de seus compromissos de campanha junto aos educadores. Revogou o decreto $\mathrm{n}^{\circ}$ 2.208/97, editado por FHC, que reformulara profundamente o ensino técnico brasileiro, particularmente a relação entre ensino médio e técnico. Contudo, para cobrir um santo, descobriu outro. Afinal, o decreto de FHC foi de fato revogado, mas através de um novo, o decreto $\mathrm{n}^{\circ} 5.154 / 04$.

De uma maneira geral, podemos dizer que o atual decreto estabelece um salto de '40 anos adiante na educação brasileira'. Senão, vejamos. Por um lado, o decreto $\mathrm{n}^{\circ}$ 2.208/97 reproduzia, de certo modo, a Reforma Gustavo Capanema, de 1942, também conhecida como 'leis' orgânicas do ensino, posto que estabelecera de forma inequívoca a dualidade estrutural do ensino brasileiro. Por outro lado, o novíssimo decreto parece inspirar-se na lei $\mathrm{n}^{\circ}$ 7.044/82, que 'reformou a re forma' do re g i memilitar (lei $\mathrm{n}^{0} 5.692 / 71$ ), retirando o caráter compulsório da profissionalização no $2^{\circ}$ grau e estabelecendo dois tipos de ensino médio: o $2^{\circ}$ grau propedêutico e o $2^{\circ}$ grau técnico.

Em outras palavras, se o decreto $\mathrm{n}^{\circ} 2.208 / 97$ recriara explicitamente a dualidade no ensino, o decreto $\mathrm{n}^{\circ} 5.154 / 04$ reconhece a dualidade, permitindo não duas, mas uma multiplicidade de possibilidades de relação entre o ensino médio e a formação profissional. Em síntese, em 2004, a legislação da educação profissional brasileira deu um salto no tempo: deixamos o ano de 1942 e avançamos até 1982 .

Logo à primeira vista, o decreto do governo Lula mostra-se bastante adequado à característica mais importante do atual padrão de acumulação, a flexibilidade, já que agrega às possibilidades anteriores - formação subseqüente, formação concomitante, interna e externa - a formação 'integrada'. Nesse sentido, o decreto parece apenas vir para acomodar interesses em conflito, como, aliás, fizera, em outro contex to, a lei $n^{\circ} 7.044 / 82$, em vez de enfrentar, via política educacional, a velha dualidade estrutural da educação brasileira.

A dualidade educacional não é, de fato, uma invenção perve rsa do sistema educacional, nem do modo de produção capitalista. Como nos ensinou o mestre Mario Manacorda (1989), a dualidade estrutural da educação é mi- 
lenar. Sendo assim, não podemos ter a veleidade de aspirar à superação da dualidade educacional, no plano da sociedade de classes, ou à sua revogação por meio de um decreto presidencial, mesmo que o atual presidente da República tenha sido eleito por um partido que se reivindica representante dos trabalhadores.

O decreto $\mathrm{n}^{\mathrm{o}} 5.154$, de 2004, regulamenta o parágr a fo $2^{\circ}$ do artigo 36 e os artigos 39 a 41 da lei $\mathrm{n}^{\circ}$ 9.394, de 20 de dezembro de 1996 - a Lei de Diretrizes e Bases (LDB) - em nove artigos ${ }^{3}$.

A primeira questão a ser levantada diz respeito à necessidade de regulamentação dos artigos em foco. Supondo, por um lado, que os artigos re feridos da LDB precisassem de regulamentação, caberia perguntar: ora, por que, então, o governo democrático de Luiz Inácio Lula da Silva não enviou um projeto de lei ao Congresso Nacional que tratasse dessa regulamentação?

Lembramos que o prime i ro governo FHC (1995-1998) assim procedera (projeto de lei $\left.\mathrm{n}^{\mathrm{o}} 1.603 / 96\right)^{4}$, até que forças sociais, notadamente os Centros Federais de Educação Tecnológica (Cefet), levantaram-se contra o conteúdo do referido projeto. Antidemocraticamente, FHC baixou o mesmo conteúdo sob a forma do famigerado decreto $\mathrm{n}^{\circ} 2.208 / 97$, que produziu rápidas e profundas tra n s formações na rede federal de educação tecnológica, nem sempre positivas. Se a forma - decreto - era, antes, antidemocrática, posto que transformou, de cima para baixo, a realidade escolar, por que agora não seria?

Por outro lado, se considerarmos que o novo decreto não muda substantivamente a ordem legal da educação profissional, mantendo apenas o estado anterior da relação entre educação regular e educação profissional, como está expressa na LDB, que apenas provê re gras mais claras para essa relação; se não provoca, de cima para baixo, transformações radicais nos 'pátios das escolas', caberia dizer que é ocioso. Em síntese, considerando-se apenas a forma e a oportunidade, podemos concluir que o decreto é antidemocrático ou ocioso.

Com relação ao artigo 1, podemos fazer pelo menos dois breves questionamentos, como veremos a seguir.

\footnotetext{
“Art. 1 A educação profissional, prevista no art. 39 da Lei n 9.394, de 20 de dezembro de 1996 (...), observadas as diretrizes curriculares nacionais definidas pelo Conselho Nacional de Educação, será desenvolvida por meio de cursos e programas de:

I - formação inicial e continuada de trabalhadores;

II - educação profissional técnica de nível médio; e

III - educação profissional tecnológica de graduação e de pós-graduação" (Brasil, 2004a).
}

Cabe perguntar o que significaria exatamente esta "formação inicial e continuada de trabalhadores". Seria o antigo 'nível básico' de educação pro- 
fissional destinado a trabalhadores 'sem escolaridade prévia', previsto no d e creto ${ }^{\circ}$ 2.208/97, mas agora travestido? Ora, se o decreto não explicita o que entende por formação inicial, caberia talvez um novíssimo decreto que regulamentasse a regulamentação pouco clara.

De fato, em outubro de 2004, foi divulgado, pela nova Secretaria de Educação Profissional e Tecnologia (Setec) do Ministério da Educação (MEC), o Projeto Escola de Fábrica. Sinteticamente, o projeto visa a

“(...) possibilitar a disseminação daqualificação profissional,sensibilizando e envolvendo organizações empresariais e unidades produtivasna preparação de re$\mathrm{c}$ u rsos humanos, compostos por jovens entre 15 e 18 anos incompletos, de baixa renda, para o exercício de uma profissão,de modo a promover a inclusão social, onde unidades de Instituições Credenciadas,que chamaremos deoperadoras, coordenem gr upos de empresas participantes, espalhadas por todo o Brasil e possam estar interagindo de forma constante com a Rede Federal de Educação Profissional" (Brasil, 2004b, p. 3, grifos do autor).

Pelo visto, o decreto $\mathrm{n}^{\circ} 5.154 / 04$ a caba também por re-inaugurar a antiga 'aprendizagem profissional', bastante semelhante àquela que deu origem ao chamado Sistema S, com a criação do Serviço Nacional de Aprendizagem Industrial, em 1942, com o decreto de lavra do presidente Vargas ${ }^{5}$.

Voltando à letra do atual decre to, ainda em seu artigo 1, pode-se também ficar um tanto confuso ao ler o inciso III. Pelo que consta, já existe uma série deregulamentações sobre graduação e pós-graduação. Por que, então, o novo decreto trata desse nível da educação? Seria a persistência da dualidade estrutural, agora na educação superior — através da 'verticalização' da educação profissional - alcançando a graduação e se prolongando para a pós-graduação? Cabe lembrar que, no Brasil, 'para o bem e para o mal', a educação superior já tem caráter profissionalizante.

Aos já existentes cursos seqüenciais, cursos superiores de tecnologia, curso normal superior, Master in Business Administration (MBA), mestrados profissionais, criados no rastro da LDB, somam-se, agora, os cursos de 'educação profissional tecnológica de graduação e pós-graduação'. Parece que só nos resta aguardar para breve uma regulamentação para o 'doutorado profissional' ou 'doutorado tecnológico'.

Cabe ainda dizer que, exceto pela 'novilíngua' do decreto atual (inciso I), os três níveis da educação profissional reproduzem tal e qual o decreto $\mathrm{n}^{\circ}$ 2.208/97, agora legalmente caduco.

A julgar que o decreto pretende 'regulamentar', ou seja, prover re gu lamento à educação profissional, o artigo 2 diz muito pouco. Diria até que provê mais dúvidas que regulamentos. 
“Art. 2 A educação profissional observará as seguintes premissas:

I - organização, por áreas profissionais, em função da estrutura sócio-ocupacional e tecnológica;

II - articulação de esforços das áreas da educação, do trabalho e emprego, e da ciência e tecnologia" (Brasil, 2004a).

Em primeiro lugar, não se esclarece devidamente "articulação de esforços das áreas da educação, do trabalho e emprego, e da ciência e tecnologia". Seria uma determinação interna à Esplanada dos Ministérios, uma ordem aos ministérios - MEC, Ministério do Trabalho e Empre go e Ministério da Ciência e Tecnologia — para que trabalhem em sinergia? Ou seria o p renúncio dos “contratos de gestão" previstos pelo Plano Diretor da Reforma do Estado, de Bresser Pereira (Brasil, 1995b)? Ou ainda o prenúncio do Projeto Escola de Fábrica?

Também é notável a ausência, no artigo 2, de 'premissas' como a "busca permanente da formação de seres humanos plenamente desenvolvidos", ou "colocar cada cidadão brasileiro na condição de poder ser governante e de controlar quem governa", ou, ainda, preparar "os indivíduos para o domínio dos recursos científicos e tecnológicos que lhes permitem utilizar as possibilidades do meio em função do bem comum6".

O conteúdo do artigo 3, principalmente em seu parágrafo $1^{\circ}$, parece exp ressar e atualizar uma das idéias mestras do decreto $\mathrm{n}^{\circ}$ 2.208: a 'modularização'. Idéia, aliás, já bastante criticada pelos educadores, por ocasião do decreto de 1997. Vejamos:

"Art. 3 Os cursos e programas de formação inicial e continuada de trabalhadores, referidos no inciso I do art. $1^{\circ}$, incluídos a capacitação, o aperfeiçoamento, a especialização e a atualização, em todos os níveis de escolaridade, poderão ser ofertados segundo itinerários formativo s, objetivando o desenvolvimento de aptidões para a vida produtiva e social" (Brasil, 2004a).

A proposta original de modularização da educação profissional é agora potencializada por meio da noção de "itinerários formativos", como indica o primeiro parágrafo:

“§ $1^{\circ}$ Para fins do disposto nocaput considera-se itinerário for mati vo o conjunto de etapas que compõem a organização da educação profissional em uma determinada área, possibilitando o ap rovei ta mento contínuo e articulado dos estudos" (Brasil, 2004a).

A modularização, ideologicamente, pro mete enfrentar o problema do desemprego com a promessa da 'empregabilidade'. Em poucas palavras, po- 
de-se dizer que, por uma inversão da realidade, o discurso hegemônico atribui ao 'módulo' o poder de produzir ocupação — como se chama agora o trabalho assalariado flexibilizado. Além disso, pressupõe uma homogeneidade dos inúmeros projetos político-pedagógicos das entidades de educação profissional, por todo o país, que a própria idéia mestra - flexibilização - desautoriza.

Como já foi dito, a dualidade não é uma invenção do sistema educacional e nem mesmo do modo de produção capitalista. Como nos ensinou o mestre Mario Manacorda (1989), a dualidade estrutural da educação atravessa os séculos, desde a constituição das sociedades divididas em classe, logo não podemos ingenuamente esperar a superação da dualidade estrutural da educação no seio de sociedades classistas. Por conseqüência, não é crível que decretos presidenciais eliminem as desigualdades sociais oriundas da estrutura de classes.

Cabe assinalar que o parágrafo $2^{\circ}$, de certa forma, naturaliza, em vez de combater, a expulsão das crianças filhas dos trabalhadores (mais explorados) da educação básica regular, destinando a esses 'desvalidos da sorte' um ramo específico de ensino: a educação de jovens e adultos (EJA) 8 + educação profissional (EP). Vejamos:

“§ $2^{\circ}$ Os cursos mencionados nocaput articular-se-ão, preferencialmente, com os cursos de educação de jovens e adultos, objetivando a qualificação para o trab alho e a elevação do nível de escolaridade do trabalhador, o qual, após a conclusão com aproveitamento dos re feridos curs o s, fará jus a certificados de formação inicial ou continuada para o trabalho" (Brasil, 2004a).

Mais uma vez, cabe apontar que o Projeto Escola de Fábrica em grande medida realiza o que apelidamos 'EJA+EP'.

Com o artigo 4, chegamos ao cerne do novo decreto, ou pelo menos àquela parte tomada como nova: a relação entre ensino médio e educação profissional. Com ele, saímos de 1942 e avançamos até 1982. A flexibilidade prevista é total 9 .

Pode-se verificar que o inciso I do artigo 4 acaba por naturalizar as diretrizes curriculares nacionais (DCN) da educação profissional de lavra de Guiomar Namo de Melo, braço direito do ex-ministro Paulo Renato de Souza.

“Art. 4 A educação profissional técnica de nível médio (...) será desenvolvida de forma articulada com o ensino médio, observados:

I - os objetivos contidos nas diretrizes curriculares nacionais definidas pelo Conselho Nacional de Educação;

II - as normas complementares dos respectivos sistemas de ensino; e

III - as exigências de cada instituição de ensino, nos termos de seu projeto pedagógico" (Brasil, 2004a). 
O primeiro parágrafo do artigo, enfim, chega à flexibilização total da relação entre o ensino médio e a educação profissional:

“§ $1^{\circ} \mathrm{A}$ articulação entre a educação profissional técnica de nível médio e o ensino médio dar-se-á de forma:

I - integrada, oferecida somente a quem já tenha concluído o ensino fundame ntal, sendo o curso planejado de modo a conduzir o aluno à habilitação profissional técnica de nível médio, na mesma instituição de ensino, contando com matrícula única para cada aluno;

II - concomitante, oferecida somente a quem já tenha concluído o ensino fundamental ou esteja cursando o ensino médio, na qual a complementaridade entre a educação profissional técnica de nível médio e o ensino médio pressupõe a existência de matrículas distintas para cada curso, podendo ocorrer:

a) na mesma instituição de ensino, ap roveitando-se as oportunidades educacionais disponíveis;

b) em instituições de ensino distintas, ap roveitando-se as oportunidades educacionais disponíveis; ou

c) em instituições de ensino distintas, mediante convênios de intercomplementaridade, visando ao planejamento e ao desenvolvimento de projetos pedagógicos unificados;

III - subseqüente, oferecida somente a quem já tenha concluído o ensino médio.

$\S 2^{\circ} \mathrm{Na}$ hipótese prevista no inciso I do $\S 1^{\circ}$, a instituição de ensino deverá, observados o inciso I do art. 24 da Lei $\mathrm{n}^{\circ}$ 9.394, de 1996, e as diretrizes curriculares nacionais para a educação profissional técnica de nível médio, ampliar a carga horária total do curs o, a fim de assegurar, simultaneamente, o cumprimento das finalidades estabelecidas para a formação geral e as condições de preparação para o exercício de profissões técnicas" (Brasil, 2004a).

Como já foi apontado, o decreto em questão mostra-se bastante adequado à característica mais importante do atual padrão de acumulação - a flexibilidade - já que regulamenta toda sorte de cursos. De fato, o decreto amplia ainda mais o leque de possibilidades de 'articulação' entre o ensino médio e a educação profissional de nível técnico, visto que prevê a possibilidade de uma formação de nível técnico 'integrada', além daquelas já arroladas no decreto $\mathrm{n}^{\circ} 2.208 / 97$, a saber, formação subseqüente e formação concomitante. Eis o cerne da flexibilidade que busca conciliar alguns dos interesses em conflito desde a promulgação do decreto $\mathrm{n}^{\circ} 2.208$, em 1997.

Nesse sentido, o novíssimo decreto parece repetir a lógica que formou a lei $\mathrm{n}^{\circ} 7.044 / 82$, na medida em que esta reconheceu lega l mente a existência, por um lado, de cursos de $2^{\circ}$ grau eminentemente propedêuticos ao $3^{\circ}$ grau, ou, mais precisamente, $2^{\circ}$ grau preparatório para o vestibular, e, por outro, de cursos técnicos de $2^{\circ}$ grau, ditos 'integrados'. Cabe lembrar que a lei 
$\mathrm{n}^{\text {o }} 5.692 / 71$ já previa a possibilidade da "concomitância externa" e mesmo da formação "subseqüente".

Enfim, caberia perguntar qual é, de fato, a inovação promovida pelo decreto $\mathrm{n}^{\circ} 5.154 / 04$. Tudo indica que, na melhor das hipóteses, o decreto ap enas reconhece (ou naturaliza) os diferentes projetos político-pedagógicos, clivados pela dualidade estrutural social, presentes na sociedade de classes em que vivemos.

O artigo 5, mais uma vez, ratifica uma indeterminação conceitual, aspecto grave já que se trata de um decreto que tem por finalidade prover re g ula mentos à LDB. Ou seja, no decre to, a educação profissional imiscui-se na educação superior, verticalizando a a primeira, ratificando "um continuum de oferta de ensino com rígida seletividade" da "formação inicial e continuada de trabalhadores" à "educação profissional tecnológica de graduação e pósgraduação" (Kuenzer, 1997, p. 48). Em outras palavras, para uns, um percurso educacional, para outros, um verdadeiro percalço escolar. Com efeito:

“Art. 5 Os cursos de educação profissional tecnológica de graduação e pós-graduação organizar-se-ão,no que concerne aos objetivos, características e duração, de acordo com as diretrizes curriculares nacionais definidas pelo Conselho Nacional de Educação" (Brasil, 2004a).

O artigo 6 apenas, e mais uma vez, retoma o decreto caduco, na me dida em que ratifica a idéia de modularização, isto é, múltiplas terminalidades ou terminalidades intermediárias da educação profissional nos níveis técnico e tecnológico.

“Art. 6 Os cursos e programas de educação profissional técnica de nível médio e os cursos de educação profissional tecnológica de graduação, quando estruturados e organizados em etapas com terminalidade, incluirão saídas intermediárias, que possibilitarão a obtenção de certificados de qualificação para o trabalho após sua conclusão com aproveitamento.

$\S 1^{\circ}$ Para fins do disposto no caput considera-se etapa com terminalidade a conclusão intermediária de cursos de educação profissional técnica de nível médio ou de cursos de educação profissional tecnológica de graduação que caracterize uma qualificação para o trabalho, claramente definida e com identidade própria. $\S 2^{\circ}$ As etapas com terminalidade deverão estar articuladas entre si, compondo os itinerários formativos e os respectivos perfis profissionais de conclusão" (Brasil, 2004a).

O artigo 7, coerente com a perspectiva da modularização e da concomitância, ratifica dois paradoxos já presentes no decreto de 1997: o legal e o pedagógico. 
“Art. 7 Os cursos de educação profissional técnica de nível médio e os cursos de educação profissional tecnológica de graduação conduzem à diplomação após sua conclusão com aproveitamento.

Parágrafo único. Para a obtenção do diploma de técnico de nível médio, o aluno deverá concluir seus estudos de educação profissional técnica de nível médio e de ensino médio" (Brasil, 2004a).

Durante as aulas da disciplina Organização da Educação no Brasil (e/ou Estrutura e Funcionamento do Ensino Médio), destinada à Pedagogia e às demais licenciaturas, é comum os estudantes questionarem o conflito legal entre 'certificação' e 'diplomação'. Querem saber o que significaria, na prática social, ser portador de um certificado de educação profissional de nível técnico ou de um diploma de técnico. Perguntam, ainda, se os portadores de certificados poderiam pedir re $\mathrm{g}$ is t ronos respectivos conselhos profissionais e se teriam os mesmos direitos profissionais daqueles que portam diplomas.

Além dessa questão, tentamos levantar a seguinte: se a formação humana - no caso, a educação profissional - seria passível de ser tão eficazmente repartida, entre o ensino médio, formação do cidadão, e o nível técnico, formação profissional, e esta, subdividida em diversos módulos, ou se o todo seria a soma mecânica das partes. Com a "educação profissional técnic a de nível médio integrada" teríamos alcançado a concepção de educação politécnica, proposta pela tradição marxista?

Por um lado, caberia perguntar: se o educando foi capaz de acompanhar satisfatoriamente o curso de educação profissional de nível técnico sem a conclusão (simultânea) do ensino médio, como lhe retirar o direito legal à diplomação? Por outro, poderíamos questionar qual seria, em pleno padrão de acumulação flexível, a qualidade de um técnico certificado, que não possui as bases científicas de sua profissão a serem construídas ao longo do ensino médio.

Em poucas palav ras, o artigo 7 ratifica a dualidade legal e profissional, entre o técnico 'de fato', isto é, certificado, e o técnico 'de direito', isto é, diplomado. Talvez esteja implícito nesta ambigüidade que caberá ao 'deusmercado' dirimir essas dúvidas de ordem legal e pedagógica.

Finalmente, os dois últimos artigos encerram talvez as maiores antinomias.

“Art. 8 Este Decreto entra em vigor na data de sua publicação.

Art. 9 Revoga-se o Decreto n ${ }^{\circ}$ 2.208, de 17 de abril de 1997.

Brasília, 23 de julho de 2004; $183^{\circ}$ da Independência e $116^{\circ}$ da República.

Luiz Inácio Lula da Silva" (Brasil, 2004a).

O presidente da República cumpriu seu compromisso de campanha: revogou o decreto $\mathrm{n}^{\mathrm{o}}$ 2.208/97. Contudo, o fez mediante outro decreto que, 
obviamente, já se encontra em vigor, e ratificado pelo CNE. Um decreto que apenas reconhece - como reconhecia a lei $\mathrm{n}^{0}$ 7.044/82 — a dualidade estrutural social e escolar e busca acomodar, de forma mais flexível e completa que o decreto $\mathrm{n}^{\circ} 2.208 / 97$, os interesses antagônicos em luta.

Resta-nos saber o que fazer diante de interesses antagônicos em luta ao longo da história. Se a dualidade é milenar, anterior ao modo de produção capitalista, se não é uma invenção autônoma da escola contemporânea, o que caberia fazer? Acreditamos que o debate sobre a concepção de educação politécnica precisa ser urgentemente retomado, de forma que possamos ter clareza do horizonte para o qual desejamos caminhar. Somente a partir daí poderemos avaliar se o ritmo, a direção e o sentido atualmente traçados são os mais adequados à luta pela superação da dualidade estrutural da educação.

\section{Origens e dimensões da educação politécnica}

Na década de 1980, o cenário educacional brasileiro foi palco de um forte debate, em cujo centro encontrava-se em disputa a reestruturação do sistema educacional brasileiro erigido durante o re gi me autoritário instaurado pelo golpe militar em $1^{\circ}$ de abril de 1964 . Toda a cena política brasileira, inclusive o campo da saúde pública, passava por um processo catártico de repensar profundamente o seu passado recente e de instaurar, a partir daí, as novas bases para a aventura da reconstrução da cidadania usurpada e reprimida.

Foi nesse contexto histórico que (re)nasceu no cenário educacional brasileiro o debate da concepção de educação politécnica, trazido por Dermeval Saviani. A presente seção busca dar conta fundamentalmente de dois aspectos.Em primeirolugar, tentar-se-á traçar um panorama do debate brasileiro sobre a politecnia; em segundo lugar, serão abordados os limites e perspectivas do debate neste novo contexto, marcado por quase 15 anos de política neoliberal.

Naqueles anos 80 , dive rsos atores sociais buscavam acertar contas com a história recente do país, que estava ainda se reencontrando com práticas democráticas formais reconquistadas.Se, para os economistas, aquela década foi 'perdida', os educadores não a encaram da mesma forma.

Os educadores, organizados em dive rsos sujeitos coletivo ${ }^{10}$, tinham c omo preocupações centrais, de um lado, o debate sobre o significado social e político da educação, particularmente a questão da escola pública, e, de outro, a preocupação em torno dos problemas relativos à 'questão salarial' do magistério.

Marcos no movimento de redemocratização foram as cinco Conferências Brasileiras de Educação (CBE), que contribuíram para a resistência às políticas educacionais emanadas do Estado autoritário em ocaso. As CBE, sem 
dúvida, reforçaram a construção dos canais de participação democrática, discutiram e elaboraram diretrizes para políticas educacionais voltadas para a maioria da população.

Com esse movimento, concentrado em torno das conferências, preparavam-se os educadores para produzir uma nova perspectiva e uma nova estrutura para o ensino brasileiro, a serem discutidas durante os debates da a l mejada Assembléia Nacional Constituinte, selando o fim da ordem estabelecida em 1964.

Derme val Saviani, depois das polêmicas causadas a partir do livro Escola e democracia(Saviani, 1986), no qual buscava não só escapar ao dilema do reprodutivismo, mas também esboçar as linhas mestras para uma pedagogia 'histórico-crítica', acaba também por desencadear o debate brasileiro sobre a politecnia.

A partir de sua atuação no Programa de Pós-Graduação em Educação, na Pontifícia Unive rsidade Católica de São Paulo (PUC-SP), no início da década de 1980, Saviani levou aos novos pesquisadores em educação os pensamentos pedagógicos de Marx e Gramsci - elab or a d ores originais da proposta de educação politécnica. Nesse contex to, em 1984, coube a Gaudêncio Frigotto (1989), então orientando de Saviani naquela instituição, produzir o primeiro texto - A produtividade da escola improdutiva - no qual é abordada explicitamente a concepção de formação politécnica.

A partir do trabalho inaugural de Frigotto, outros se seguiram, tais como os de Lucília Machado (1989) e Acácia Kuenzer (1988, 1991), além de outros de autoria do próprio Frigotto (1991a, 1991b) e de Saviani (1989, 2003)11. Portanto, pode-se afirmar que o debate sobre a politecnia tomou vulto no Brasil, dentro do contexto de redemocratização política, na busca de reestruturação da educação nacional. Atingiu seu ápice no final dos anos 1980 e início dos 1990, por ocasião do debate e da promulgação da nova Constituição brasileira, que, por sua vez, demandou a elaboração de uma série de leis complementares. Com efeito, instituída a nova carta, os educadores passaram a envidar esforços na elaboração de uma nova LDB, só promulga da em dezembro de 199612.

No Brasil, a discussão de idéias sobre a concepção de educação politécnica foi calcada fundamentalmentena contribuição teórica dos autores citados. Nessa perspectiva, o conceito de politecnia pode ser captado a partir da confluência de três eixos fundamentais: dimensão infra-estrutural, dimensão utópica e dimensão pedagógica (Rodrigues, 1998a).

A identificação simultânea dessas três dimensões nos discursos científicos que assumem o debate da politecnia revela uma importante unidade entre os autore s, superando a mera repetição vazia de umslogan. Nessa perspectiva, buscar-se-á, a seguir, explicitar sumariamente as três dimensões que compõem a concepção de formação politécnica. 
A dimensão infra-estrutural da concepção politécnica de educação agrega os aspectos relacionados ao mundo do trabalho, especificamente os processos de trabalho sob a organização capitalista de produção, e, conseqüentemente, a questão da qualificação profissional.

Apesar de os aspectos apresentados não serem recentes, eles tiveram destaque, na época, em função da discussão sobre os impactos provocados pelas chamadas 'novas tecnologias' - face mais imediata do padrão de acumulação flexível que emergia no Brasil — sobre os processos de trabalho.

Pode-se afirmar que a discussão sobre a qualificação profissional, com base nas novas formas de organização do processo de trabalho, era o ponto focal da discussão da educação politécnica. Portanto, a dimensão infra-estrutural da concepção politécnica de educação se relaciona intimamente com as mudanças na produção e com suas correlatas alterações científicas e, principalmente, tecnológicas.

Tais mudanças estariam apoiadas numa 'tríade re volucionária': energia nuclear, biotecnologia e microeletrônica. Essas mudanças, segundo os autore s, propiciariam alterações qualitativa mente distintas daquelas operadas pelas re voluções industriais anteriores, tanto nos meios e instrumentos de produção, quanto nos serviços, assim como as mudanças operadas na base técnica do trabalho humano, simul ta nea mente, propiciariam e demandariam uma qualificação profissional de novo tipo.

No entanto, na medida em que os autores percebem que 'contradição' é um aspecto inerente a qualquer atividade humana, é impossível atribuirse um caráter unicamente 'positivo' ou 'negativo' às novas tecnologias.

Nesse sentido, os pesquisadores em educação que abordam a questão da politecnia primeiramente assumem que o trabalho humano é, inevitave lmente, cada vez mais mediado pela tecnologia. Portanto, não se devem buscar nas formas 'primitivas' de trabalho, na defesa do artesanato, nos métodos pedagógicos firmados na relação mestre-ap rendiz, as bases da concepção de educação politécnical3.

A questão torna-se então procurar esclarecer como as inovações tecnológicas vêm 'implicando' a politecnia, ou seja, em que medida as mudanças nos processos de trabalho estariam contribuindo para a efetivação de uma formação politécnica.

Dada a simplificação das tarefas laborais, mediadas pela máquina e pela uniformização dos processos de trabalho, o trabalhador teria a possibilidade de atuar em todas as etapas do processo de trabalho. Logo, o desenvolvime nto atual dos meios e instrumentos de produção demandaria a polivalência do trabalhador. As mudanças tecnológicas contemporâneas, portanto, não só dispensariam o trabalhador formado pelo estreito padrão taylorista-fordista, como a manutenção deste padrão traria entraves ao próprio desenvolvimento da produção capitalista. 
Entender que a mudança no conteúdo e na forma do trabalho está ampliando a crise do modelo taylorista-fordista de produção, demandando, assim, um novo tipo de trabalhador - o polivalente — não significava, para aqueles autores, um determinismo tecnológico, tampouco o abandono da perspectiva da superação das relações sociais de produção capitalistas. Em outras palavras, os autores não identificavam polivalência com politecnia. A polivalência representaria uma dimensão, um aspecto necessário à politecnia, ainda significando uma demanda adstrita à lógica capitalista de estruturação do processo de trabalho. Manter-se nos limites da polivalência do trabalhador seria conferir ao capitalismo,ou à tecnologia que o sustenta, o poder de mecanicamente ultrapassar-se.

O trabalho sob o modo de produção capitalista - mesmo que moderno, polivalente, flexível - continua, fundamentalmente, regido pelas 'leis' do capital e, portanto, pela alienação do e no trabalho.

A concepção de educação politécnica, principalmente em sua dimensão infra-estrutural, define-se na luta pela liberdade no trabalho, na medida em que busca métodos de reconstrução da identidade do trabalhador com o produto de seu trabalho, por meio da mediação da compreensão totalizante do p rocesso de trabalho. Esse tipo de compreensão abrir-lhe-ia caminho para uma atuação mais ampla, propiciada pela polivalência, no processo de produção da existência. Politecnia pressupõe, assim, domínio teórico-prático do processo de trabalho.

Em suma, o que a concepção politécnica de educação propõe, em sua di mensão infra-estrutural, é a identificação de estratégias de formação humana, com base nos modernos processos de trabalho, as quais apontem para uma reapropriação do domínio do trabalho.

O segundo vetor do debate brasileiro sobre a educação politécnica - a dimensão utópica14 — não tem como objetivo mostrar que a politecnia seria um ideal irrealizável, uma proposta historicamente desenraizada; ao contrário, busca expor a profunda relação entre essa concepção de formação humana e um projeto de construção de uma sociedade socialista.

$\mathrm{Na}$ verdade, para aqueles autores, seria o projeto utópico-re volucionário de uma nova sociedade que possibilitaria, por um lado, proporcionar uma unidade teórico-política à concepção politécnica de educação e, por outro, impedir a sua 'naturalização'. Em outras palavras, ao se dar ênfase à dimensão infra-estrutural, isto é, às mudanças contemporâneas nos processos de trabalho, a partir da nova Revolução Industrial, poder-se-ia chegar ao equívoco de se entender que a formação politécnica é o caminho natural demandado pelo modo de produção capitalista. Ao contrário, a politecnia representa uma profunda ruptura com o projeto de qualificação profissional e, fundamentalmente, com o projeto de formação humana postos pela sociedade burguesa, “a concepção de ensino e formação politécnica é, antes de 
tudo, uma crítica radical ao projeto excludente, elitista e dife renciador do ensino e da formação, desenvolvido na sociedade capitalista" (Frigotto, 1991a, p. 270).

A concepção de educação politécnica pressupõe uma visão social de mundo radicalmente distinta daquela que, hegemonicamente, se apresenta nas sociedades atuais. Partindo de uma apreensão das mudanças ocorridas no mundo do trabalho, mediatizada por uma visão social que rompe com as visões burguesas de homem, sociedade e trabalho, a concepção politécnica de educação acaba por desaguar em sua dimensão pedagógica.

Como caminhar para uma progressiva, e necessária, explicitação do $\mathrm{mo}$ dus operandi de uma escola que se paute numa orientação politécnica, sem recair em proposições abstratas, isto é, historicamente desenraizadas ${ }^{15}$ ?

De um lado, faz-se necessário o contínuo estudo da materialidade social da qual a educação é parte integrante, em particular, dos sempre renovados processos de trabalho. De outro, é preciso ressaltar que nenhum estudo ou pesquisa poderá substituir a práxis educativa desenvolvida a partir do horizonte da politecnia. Isto é, a construção de uma concepção de educação politécnica precisa, necessariamente, estar embasada em práticas pedagógicas concretas que, por sua vez, devem se apoiar em profundas reflexões teóricas sobre o papel e a natureza da educação na sociedade capitalista16.

Feitas essas considerações gerais, pode-se ainda destacar, no quadro da produção teórica brasileira, alguns vetores norteadores para a organização do ensino de caráter politécnico.

Dentre esses vet ores, pode-se destacar, em prime i rolugar, a perspectiva que propõe a politecnia como uma proposta privilegiadamente ligada ao ensino médio. De maneira geral, a concepção de politecnia vem sendo entendida, pelos autores brasileiros, como um momento especial de 'explicitação' do trabalho no cenário escolar (Saviani, 2003).

A escola politécnica situa-se, pois, segundo alguns autores 17 , entre a formação fundamental, em que o trabalho determina o currículo escolar de forma 'implícita', e a profissionalização não constitui objetivo específico, e a formação de nível superior, em que o trabalho e a profissionalização são objetivos muito claros.

Outro aspecto, complementar ao primeiro, é a forma pela qual se dará essa explicitação do trabalho. Neste ponto existem algumas tensões ex plícitas, em que alguns pesquisadores defendem uma formação básica para o trabalho industrial moderno, sem o caráter dado pelas habilitações profissionais. Ou seja, a educação politécnica não teria entre seus objetivos a p reparação de técnicos de nível médio, mas a formação de cidadãos capazes de compreender a totalidade e os fundamentos científicos e técnicos do mundo do trabalho, estando, assim, aptos a intervir nessa realidade sócio-técnica. 
Outros autores entendem que a formação de técnicos não é um objetivo excludente a esses aportes. Para esses autores, é possível a formação de técnicos de nível médio sob a perspectiva da politecnia.

Um terc e irogrupo de autores busca um ponto de equilíbrio entre essas duas vertentes, pretendendo uma escola politécnica em dois momentos: a pri meira etapa daria conta daquela formação necessária a uma compreensão totalizante do fenômeno e do fato do trabalho, enquanto a profissionalização stricto sensu seria concretizada numa segunda etapa: no próprio nível médio, para uns e, para outros, no chamado pós-secundário.

Em que pesem essas diferenças, por vezes artificialmente ampliadas, o que sobressai por ser o aspecto de maior concordância entre os pesquisadores é a natureza dessa explicitação ou dessa profissionalização. É consenso entre os autores que a formação politécnica busca romper com a profissionalização estreita e também com a educação geral e propedêutica, livre sca e descolada do mundo do trabalho.

O que se mostrava como tendência naquele debate, portanto, era a defesa de uma formação que desse conta dos fundamentos técnicos, científicos e também de gestão, comuns ao trabalho moderno. Além disso, advogava-se uma formação que, partindo desse núcleo, não transformasse as 'distintas' áreas do conhecimento em instrumentos pragmáticos, supostamente a serviço da profissionalização. Ou seja, uma formação que tomasse esses dive rsos campos científicos como suporte para uma compreensão da totalidade dos processos de trabalho nos quais os educandos estivessem sendo introduzidos ou dos quais já fizessem parte.

\section{Tempo, espaço e horizonte da politecnia}

As conjunturas brasileira e mundial propuseram uma questão fundamental: saber se a politecnia tem futuro ou se está irremediavel mente imobilizada no museu da história, seja pelo conteúdo anacrônico, seja pelo horizonte ultrapassado.

A concepção de educação politécnica está indissoluve l mente ligada ao pensamento de Karl Marx e Antonio Gramsci, sendo datada, portanto, no fim do século XIX e início do século XX18. Marx presenciou a explosão dos gigantescos complexos fabris, aglutinando centenas de operários, inclusive crianças, embrutecidos, me ros apêndices da maquinaria. Gramsci foi um observador atento do nascimento daquilo que ele próprio denominou de fordismo, conceito hoje bastante disseminado.

Esses autores foram testemunhas perspicazes de um tempo no qual a dominação do homem pela máquina o reduziu a peça intercambiável do complexo industrial, impelindo-o à repetição compulsiva dos gestos laborais. 
No entanto, o capitalismo, desde o fim do século XIX, vem, inegave lmente, sofrendo processosmeta mórficos.O liberalismo foi varrido pela Segunda Guerra Mundial, reaparecendo,em fins da década de 1970, sob o rótulo de neoliberalismo; o fo rdismo teve sua morte proclamada pelo ingresso da microeletrônica nas fábricas, anunciando a acumulação flexí vel; todos os re gi mes de países que se autoproclamavam socialistas foram à bancarrota19, encetando hoje esforços para integrarem-se ao me rcado globalizado. Todos os cientistas sociais em uníssono proclamam: o mundo mudou.

Desde 1989, o Brasil me rgulhou numa conjuntura política bastante adve rsa ao debate e à defesa da educação politécnica. Com efeito, a eleição de Fernando Collor, para a presidência, e, em seguida, a de Fernando Henrique Cardoso marcaram o ingresso das políticas neoliberais ${ }^{20}$. Tais políticas vêm, de um lado, no rastro da crise do padrão de acumulação fordista, iniciada em fins da década de 1970, e na conseqüente estruturação do novo padrão de acumulação flexível; de outro, no esteio da crise do pensamento anticapitalista, diante da derrocada da União Soviética e do restabelecimento da economia capitalista em todo o Leste Europeu, e, agora, pela continuidade das políticas macroeconômicas, sociais e educacionais do governo de Luís Inácio Lula da Silva.

Enfim, a sociedade contemporânea encontra-se diante do seguinte e c rescente dilema: por um lado, crescem as possibilidades materiais e tecnológicas para a dilatação do reino da liberdade; por outro, diminuem os direitos sociais, ampliando o reino da necessidade. Ou seja, o avanço incomensurável do desenvolvimento das forças produtivas, que poderiam servir de b ase à educação politécnica, acaba por esbarrar nos limites da organização da vida social. Tal forma acaba por entravar o desenvolvimento do debate e das práxis educativas de caráter politécnico.

O debate brasileiro da politecnia, como já foi dito, esteve, de certa forma, bastante vinculado à elaboração de uma nova LDB que rompesse com o aparato legal educacional instituído pelo regime militar. Com efeito, o primeiro esboço de um projeto de LDB foi realizado por Saviani, no qual podia-se ler:

“Art. 35 A educação escolar de $2^{\circ}$ grau (...) tem por objetivo geral propiciar aos adolescentes a formação politécnica necessária à compreensão teórica e prática dos fundamentos científicos das múltiplas técnicas utilizadas no processo produtivo" (Saviani, 1988, p. 20).

Após anos de debates21, a nova LDB foi promulgada em dezembro de 1996. Saviani (1997), analisando o texto da nova LDB, no que tange ao ensino médio, afirma: 
“Essa idéia de politecnia, que havia orientado a elaboração da proposta preliminar por mim apresentada, foi se descaracterizando ao longo do processo, restando dela, na lei, apenas o inciso IV do artigo 35 que proclama como finalidade do ensino médio 'a compreensão dos fundamentos científico-tecnológicos dos processos pro d u ti vos' reiterado pelo inciso I do parágrafo prime i ro do artigo 36: 'domínio dos princípios científicos e tecnológicos que presidem a produção moderna'" (Saviani, 1997, p. 213).

Prosseguindo, o autor, ratificando o que foi exposto por esse ensaio, entende que "esse desfecho era previsível", já que:

“A curto prazo, teríamos que caminhar bastante antes de poder viabilizá-la. Há certas mudanças sociais que necessitam ser desenvolvidas no âmbito político e econômico para que uma proposta como essa possa se viabilizar" (Saviani, 1997, p. 213).

E conclui o autor:

“Passados mais de dez anos, se por um lado o avanço tecnológico vem evidenciando a relevância dessa discussão, por outro lado, as condições políticas traduzidas nos mencionados conflitos, disputas e jogo de interesses tornaram a situação ainda mais adve rsa. E esse quadro está refletido no texto da nova LDB" (Saviani, 1997, p. 214).

Logo após a pro mulgação da nova LDB, o governo brasileiro reti rou do Congresso Nacional seu anteprojeto de lei, que regulamentaria os artigos sobre educação profissional contidos na recente lei educacional promulgada. Em vez do debate democrático, o Executivo optou por impor a regulamentação com o decreto $n^{\circ} 2.208$, de 17 de abril de 1997. Esse decreto estabelece que a educação profissional tenha por objetivo (artigo 2), entre outros,

“III - qualificar e requalificar para o mercado de trabalho jovens e adultos com qualquer nível de escolaridade" (Brasil, 1997).

De forma análoga, no artigo 4, pode-se ler:

"A educação profissional abrange os seguintes níveis:

I - básico - destinado a qualificação e requalificação básicas de trabalhadores independentes de escolaridade" (Brasil, 1997, grifo nosso).

Marise Nogueira Ramos, analisando o (então) projeto de educação profissional, conclui que a separação entre formação geral e formação profissional "ao invés de realizar a síntese da teoria com a prática, do concreto com o abs- 
trato, como desejam os empresários, torna-se, na verdade, um entrave para esta realização" (ETFQ, 1996, grifos nossos).

Em 23 de julho de 2004, com o decreto $\mathrm{n}^{\circ}$ 5.154, a história se repetiu. Mais uma vez, em nome do 'possível', do 'viável', o termo e o conceito de politecnia foram expurgados das normas legais que ordenam a educação brasileira. Resta saber se permanecerão, novamente, à margem do debate político-pedagógico.

\section{Considerações finais}

Ainda hoje, como evidencia qualquer revisão de literatura atual sobre o futuro do mundo do trabalho, deparamo-nos com aparentes e inesperados consensos supraclassistas. Todos os sujeitos sociais parecem concordar que a revolução microeletrônica impõe à sociedade a formação de indivíduos capazes de lidar com um mundo em transformação. Todos parecem concordar que a formação profissional de novo tipo precisa alicerçar-se na sólida educação geral e básica, e no conhecimento dos fundamentos técnico-científicos que sustentam as novas tecnologias. Enfim, da intelectualidade aos sindicatos, passando pelas organizações patronais, todos parecem concordar que a formação humana precisa adequar-se aos rápidos movimentos da chamada sociedade pós-industrial.

No entanto, as políticas educacionais brasileiras — de Collor a Lula parecem não ir ao encontro daqueles consensos. Ao contrário, empregabilidade e aligeiramento da qualificação profissional aparecem em um estranho e contraditório entrelaçamento, como objetivos para a educação profissional do trabalhador brasileiro do século XXI.

Como nos ensinou Saviani (2003), na sociedade capitalista, a ciência, o conhecimento converte-se em força produtiva, em meio de produção. Nesse sentido, deveria ser de propriedade privada da burguesia. Contudo, se os trabalhadores fossem completamente ex p ropriados do conhecimento, eles não poderiam produzir mercadorias, produzir mais-valia. “Desse modo, a sociedade capitalista desenvolveu mecanismos através dos quais procura expropriar o conhecimento dos trabalhadores e sistematizar, elaborar esses conhecimentos, e devolvê-los na forma parcelada" (Saviani, 2003, p. 137).

Ora, a dualidade estrutural da educação, a frag mentação da formação humana é, sem dúvida, um dos mecanismos utilizados pelo Capital para lidar com a contradição posta entre a necessidade de educar o trabalhador para produzir e a interdição da socialização dos conhecimentos socialmente produzidos.

Em suma, uma dupla determinação identifica precisamente o caráter contraditório do período histórico e conjuntural no qual o debate educacional 
está inserido e, em particular, o debate sobre a politecnia e sobre a atual nova reforma da educação profissional.

Por um lado, a crise do modelo fo rdista e a conseqüente implantação da especialização flexível vêm trazendo profundas mudanças nos perfis de qualificação da força de trabalho, não só na indústria, mas praticamente em todos os setores do mundo do trabalho. Essas mudanças apontam para a superação do perfil de um trabalhador pouco escolarizado, adestrado em uma única (curta e extremamente simples) rotina laboral. A emergência de um novo perfil de trabalhador demandado pela especialização flexível, na verdade, vem confirmar o otimismo de Marx a respeito das conseqüências do maquinismo e da grande indústria sobre o futuro do trabalho, conseqüências estas que deram sustentação à sua proposta de educação politécnica.

Por outro lado, a crise do pensamento anticapitalista aliada à crise regulatória do padrão de acumulação fordista, isto é, do keynesianismo, abriu caminho para o renascimento do pensamento liberal-conservador. Esse pensamento, tornado força material com as políticas neoliberais, transmutou as virtuosidades - econômicas, sociais e formativas - da reestruturação produtiva em virulenta ameaça, não só ao trabalho, mas também à própria vida de gigantescos contingentes de seres humanos por todo o globo.

O trabalho industrial sob o incipiente capitalismo precisou ser imposto à força àqueles que não se submetiam às demandas da nova sociedade urbano-industrial. Hoje, os trabalhadores precisam lutar pelo direito de serem explorados pelo capital, que vem incessantemente substituindo o trabalho vivo pelo trabalho morto.

Enfim, a sociedade contemporânea encontra-se diante do seguinte e crescente dilema: por um lado, crescem as possibilidades materiais para a dilatação do reino da liberdade; por outro, diminuem os direitos sociais, ampliando o reino da necessidade.

O mundo do trabalho que vem demandando trabalhadores altamente escolarizados e polivalentes é o mesmo que vem destruindo empregos e conformando a juventude ao cinismo e ao individualismo consumista exacerbado. O caráter foi corroído (Sennett, 2000).

A defesa de uma educação politécnica, estruturada com base na necessidade da ap reensão dos processos de produção do conhecimento subjacentes ao trabalho e das bases científicas, técnicas e de gestão comuns a esses processos, não se pode apoiar numa visão ingênua das virtuosidades da atual revolução científico-tecnológica, tampouco pode ser construída sob a perspectiva de que o modo de produção capitalista é insuperável.

Em outras palavras, a defesa, hoje, de uma educação que tenha por horizonte a politecnia passa necessariamente pela negação do avanço do Capital sobre o Trabalho; passa necessariamente pela negação de uma pedagogia societária, baseada no cinismo; passa necessariamente pela negação de uma educ a- 
ção escolar fragmentada e direcionada para a competitividade e a empre gab ilidade; passa, enfim, pela afirmação da solidariedade e da liberdade humanas. Assim, por um lado, defender a politecnia é, num certo sentido, caminhar na contramão da conjuntura, dessa interminável década de 1990. Mas, por outro lado, hoje, defender e construir a educação politécnica impõe-se como uma tare fa necessária para aqueles que, apesar das diretrizes da atual política educacional, lutam por uma educação omnilateral para a classe trabalhadora. Enfim, a tare fa educacional daqueles que têm como horizonte a sociedade sem classes permanece a mesma: lutar pelo que é necessário.

\section{Agradecimentos}

A Kênia Miranda pelas inúmeras e fundamentais contribuições.

\section{Notas}

1 Professor da Faculdade de Educação da Unive rsidade Federal Fluminense (UFF), membro do Núcleo de Estudos, Documentação e Dados sobre Trabalho e Educação (Neddate-UFF) e pesquisador do CNPq. Doutor em Educação pela Universidade Estadual de Campinas. <jrodrig@vm.uff.br>

2 Esta seção é uma versão revista e ampliada do texto "Quarenta anos adiante: breves anotações a respeito do novo decreto de educação profissional" (Rodrigues, 2005).

3 Em que pese a transcrição do texto legal tornar a leitura um tanto cansativa, optamos por fazê-lo para evitar que o leitor tenha que proceder ele mesmo ao cotejamento.

4 Para uma análise do projeto de lei no. 1.603/96 e, por extensão, do decreto no. 2.208/97, ver Kuenzer (1997).

5 Sobreas práticas e o pensamento da burguesia industrial entre as décadas de 1930 e 1940, ver Rodrigues (1998b).

6 Excertos do artigo 1 do prime i ro projeto de LDB ap resentado à Câmara dos Deputados em dezembro de 1988 (Brasil, 1988).

7 Sobre essa questão, ver Rodrigues (1997). 
8 A educação de jovens e adultos é uma 'modalidade' de educação prevista nos artigos 37 e 38 da lei no. 9.394/96 (LDB) “destinada àqueles que não tiveram acesso ou continuidade de estudos no ensino fundamental e médio na idade própria" (Brasil, 1996).

9 Antes, contudo, por conta dos artigos 4 e 5, cabe uma pequena digressão preliminar sobre o papel do Conselho Nacional de Educação (CNE). Deve-se lembrar que, pela lei no. 9.131/95, o CNE é me ro órgão assessor do ministro da Educação. Nesse sentido, se o a tual governo pretendesse aplicar o princípio da Gestão Democrática (artigo 3, inciso VIII, lei no. 9.394/96) ao ramo público do chamado sistema educacional brasileiro, caber-lhe-ia enviar ao Congresso Nacional um projeto de lei que reestruturasse o CNE. Essareestruturação, em nossa opinião, deveria conferir ao CNE caráter autônomo, além de reformular sua composição e respectivos procedimentos de escolha dos conselheiros.

10 Associação Nacional de Educação (Ande), Associação Nacional de Pós-Graduação e Pesquisa em Educação (Anped), Associação Nacional de Docentes do Ensino Superior (Andes), e as entidades regionais ligadas à então Confederação de Professores do Brasil (CPB), atual Confederação Nacional dos Trabalhadores da Educação (CNTE).

11 O texto Sobre a concepção de politecnia, produzido e divulgado em 1987, publicado originalmente em 1989, foi atualizado e publicado sob o título O choque teórico da politec nia (Saviani, 2003).

12 Sobre o longo e complicado processo de elaboração da nova LDB (lei no. 9.394), ver Saviani (1997).

13 Sobre a o artesanato, seus métodos pedagógicos e a visão nostálgica que geralmente o envolve, ver Rugiu (1998), além da proposta de Pistrak (2002).

14 Pelo reconhecimento da importância das propostas educacionais inicialmente postas por Robert Owen, continuadas e ampliadas por Marx, e, fundamentalmente, pelo intenso desejo, ex presso pelos socialistas utópicos, de contribuir para que a humanidade alcance uma sociedade sem classes é que adotamos a ex p ressão dimensão 'utópica', para estabelecer uma das características da concepção politécnica de educação. Contudo, diante do discurso redivivode que a história 'chegou a fim', caberia, talvez, passar a denominar essa dimensão de socialista.

15 Para uma crítica contundente ao escolacentrismo e a à pers pectiva do 'dever ser', ver Arroyo (1991).

16 Sobre uma prática pedagógica desenvolvida na Escola Politécnica de Saúde Joaquim Venâncio nessa perspectiva, ver Martins, Ferreira e Rodrigues (1996).

17 Mesmo considerando as distintas contribuições provenientes, principalmente, dos autores citados, o presente texto realiza uma abstração das tensões internas do debate brasileiro sobre a politecnia. Caso seja do interesse do leitor conhecer com maiores detalhes a discussão da politecnia, no Brasil, inclusive as diferentes abordagens construídas por autores como Acácia Kuenzer, Derme val Saviani, Gaudêncio Frigotto e Lucília Machado, sugere-se a leitura de Rodrigues (1998a).

18 Sobre o pensamento pedagógico de Marx e Gramsci, ver Manacorda (1990 e 1991).

19 Sobre os debates sobre a politecnia no nascente Estado soviético, ver Machado (1991). 
20 Sobre o neoliberalismo, ver Boito Jr. (1999).

${ }^{21}$ Essa trajetória é retratada e analisada detalhadamente por Saviani (1997).

\section{Referências}

ARROYO, Miguel. 1991. Revendo os vínculos entre trabalho e educação: eleme ntos materiais da formação humana. In: SILVA, Tomaz Tadeu (org.). Trabalho, educação e prática social: por uma teoria da formação humana. Porto Alegre: Artes Médicas.

BOITO JR., Armando. 1999. Política neoliberal e sindicalismo no Brasil. São Paulo: Xamã.

BRASIL. 1971. Lei no. 5.692, de 11 de agosto de 1971. Fixa diretrizes e bases para o ensino de $1^{\circ}$ e $2^{\circ}$ graus, e dá outras providências.

1982. Lei no. 7.044, de 18 de outubro de 1982. Altera dispositivos da Lei 5.692, de 11 de agosto de 1971, referentes a profissionalização do ensino de $2^{\circ}$ grau.

. 1988. Projeto de LDB no. 1258-A (de autoria do deputado Octávio Elísio). Diário do Congresso Nacional, n. 175. (Suplemento).

1995a. Lei no. 9.131, de 24 de novembro de 1995. Altera dispositivos da Lei 4.024, de 20 de dezembro de 1961, e dá outras providências.

1995b. Plano Diretor da Reforma do Aparelho do Estado. Disponível em: <www.planalto.gov.br/publi_04/colecao/ plandi.htm>. Acesso em: 30 nov. 2004. 1996. Lei no. 9.394, de 20 de dezemb ro de 1996. Estabelece as Diretrizes e Bases da Educação Nacional. 1997. Decreto no. 2.208, de 17 de abril de 1997. Regulamenta o $\S 2^{\circ}$ do art. 36 e os art. 30 a 42 da Lei no. 9.394, de 20 de dezembro de 1996, que estabelece as Diretrizes e Bases da Educação Nacional. . 2004a. Decreto no. 5.154, de 23 de julho de 2004. Regulamenta o $\S 2^{\circ}$ do artigo 36 e os arts. 39 a 41 da lei no. 9.394, de 20 de dezembro de 1996, que estabelece as diretrizes e bases da educação nacional e dá outras providências.

. 2004b. Projeto Escola de Fábrica. Brasília: MEC. Disponível em: <www.mec. gov.br/semtec/escola/projeto.pdf $>$. Acesso em: 20 jul. 2005.

ETFQ-RJ (Escola Técnica Federal de Química do Rio de Janeiro). 1996. Análise do projeto de lei que dispõe sobre a educação profissional, a organização da rede fede ral de educação profissional, e dá outras providências. Rio de Janeiro: ETFQ-RJ. (Mimeo).

FRIGOTTO, Gaudêncio. 1989. A produtivi dade da escola improdutiva: um (re)ex ame das relações entre educação e estrutura econômico-social capitalista. $3^{\text {a }} \mathrm{ed}$. São Paulo: Cortez/Autores Associados. 1991a. Trabalho-educação e tecnologia: tre in a mento polivalente ou for mação politécnica? In: SILVA, Tomaz Tadeu (org.). Trabalho, educação e prática social: por uma teoria da formação humana. Porto Alegre: Artes Médicas. 1991 b. Tecnologia, relações sociais e educação. Tempo Brasileiro, n. 105, p. 131-148.

HARVEY, David. 1992. Condição pós-moder $n$ a: uma pesquisa sobre as origens da mudança cultural. $5^{a}$ ed. São Paulo: Loyola. 
KUENZER, Acácia. 1988. Ensino de $2^{\circ}$ grau: o trabalho como princípio educativo. São Paulo: Cortez.

1991. Ensino médio: uma nova concepção unificadora de ciência, técnica e ensino. In: BRASIL. Politecnia no ensino médio. São Paulo-Brasília: Cortez/Ministério da Educação.

1997. Ensino médio e profissional: as políticas do Estado neoliberal. São Pa ulo: Cortez.

MACHADO, Lucília. 1989. Politecnia, escola unitária e trabalho. São Paulo: Cortez/ Autores Associados.

1991. A politecnia nos debates pedagógicos soviéticos das décadas de $20 \mathrm{e}$ 30. Teoria \& Educação, n. 3, p. 151-174.

MANACORDA, Mario A. 1989. Históra da educação: da Antiguidade aos nossos dias. $2^{a}$ ed. São Paulo: Cortez/Autores Associados.

1990. O princípio educativo em Gramsci. Porto Alegre: Artes Médicas.

1991. Marx e a pedagogia moderna. São

Paulo: Cortez/Autores Associados.

MARTINS, Carla M.; FERREIRA, Cristiane D.; RODRIGUES, José. 1996. O estudo dos processos de trabalho em saúde e a educação politécnica. In: EPSJV (Escola Politécnica de Saúde Joaquim Venâncio) (org.). Formação de pessoal de nível médio para a saúde: desafios e pers pe ctivas. Rio de Janeiro: Fiocruz, p. 193-205.

PISTRAK. 2002. Fundamentos da escola do trabalho. $2^{\text {a }}$ ed. São Paulo: Expressão Popular.

RODRIGUES, José. 1997. Da teoria do capital humano à empregabilidade: um ensaio sobre as crises do Capital e a Edu- cação Brasileira. Trabalho \& Educação, n. 2, p. 215-230.

1998a. A educação politécnica no Bra sil. Niterói: EdUFF.

. 1998b. O moderno príncipe industrial: o pensamento pedagógico da Confederação Nacional da Indústria. Campinas: Autores Associados.

2005. Quarenta anos adiante: breves anotações a respeito do novo decreto de educação profissional. Trabalho Neces sário, n. 3. Disponível em: <www.uff. $\mathrm{br} /$ trabalhonecessario/JoseRodrigues TN3.htm>. Acesso em: 21 jun. 2005.

RUGIU, Antonio Santoni. 1998. Nostalgia do mestre artesão. Campinas: Autores Associados.

SAVIANI, Derme val. 1986. Escola e democracia. $11^{\text {a }}$ ed. São Paulo: Cortez/Autores Associados. 1988. Co n tribuição à elaboração da no va Lei de Diretrizes e Bases da Educação: um início de conversa. (Mimeo). 1989. Sobre a concepção de politecnia. Rio de Janeiro: Politécnico da Saúde Joaquim Venâncio, Fundação Oswaldo Cruz. . 1997. A nova lei da educação: LDB trajetória, limites e perspectivas. Campinas: Autores Associados.

2003. O choque teórico da politecnia. Trabalho, Educação e Saúde, v. 1, n. 1, p. 131-152.

SENNETT, Richard. 2000. A corrosão do ca ráter: conseqüências pessoais do trabalho no novo capitalismo. $4^{\mathrm{a}}$ ed. Rio de Janeiro: Record.

Recebido em 29/12/2004

Aprovado em 30/05/2005 